Article

\title{
Extracting Minerals from Seawater: An Energy Analysis
}

\section{Ugo Bardi}

Dipartimento di Chimica, Università di Firenze, Polo scientifico di Sesto Fiorentino, 50019 Sesto Fiorentino (Fi), Italy; E-Mail: ugo.bardi@unifi.it; Tel.: +39-55-457-3118; Fax: +39-55-457-3120.

Received: 10 February 2010; in revised form: 23 March 2010 / Accepted: 29 March 2010 /

Published: 9 April 2010

\begin{abstract}
The concept of recovering minerals from seawater has been proposed as a way of counteracting the gradual depletion of conventional mineral ores. Seawater contains large amounts of dissolved ions and the four most concentrated metal ones ( $\mathrm{Na}, \mathrm{Mg}, \mathrm{Ca}$, $\mathrm{K}$ ) are being commercially extracted today. However, all the other metal ions exist at much lower concentrations. This paper reports an estimate of the feasibility of the extraction of these metal ions on the basis of the energy needed. In most cases, the result is that extraction in amounts comparable to the present production from land mines would be impossible because of the very large amount of energy needed. This conclusion holds also for uranium as fuel for the present generation of nuclear fission plants. Nevertheless, in a few cases, mainly lithium, extraction from seawater could provide amounts of metals sufficient for closing the cycle of metal use in the economy, provided that an increased level of recycling can be attained.
\end{abstract}

Keywords: mineral extraction; uranium supply; lithium supply; copper supply; nuclear fission; nuclear fusion

\section{Introduction}

The progressive depletion of high grade ores is gradually forcing the extractive industry to move to lower grade ores. These low grade ores are often more abundant in terms of theoretically recoverable amounts, but are more expensive in terms of the energy needed for extraction. This progressively increasing requirement generates lower economic returns. As a consequence, supplying the economy with a steady flux of minerals at reasonable costs is already becoming a problem for some minerals [1-3] and may become so for more minerals in the future. This phenomenon has been modelled, e.g., in [4]. 
In the case of fossil fuels the problem is similar and it is referred to as one of declining EROEI (energy return for energy invested) [5].

The oceans contain immense amounts of dissolved ions which, in principle, could be extracted without the complex and energy intensive processes of extraction and beneficiation which are typical of land mining. In addition, an important fraction of the minerals which are lost as waste at the end of the economic process end up in the sea as dissolved ions. In this sense, the oceans could be considered an infinite repository of materials that could be used for closing the industrial cycle and attain long term sustainability.

Minerals have been extracted from seawater from remote times, the classic example being sodium chloride, the common table salt. Today, the four most concentrated metal ions in seawater ( $\mathrm{Na}, \mathrm{Mg}$, Ca and K) are commercially recovered. Several attempts have been made to extend this range but, so far, with no success. Mining seawater had become popular during the "oil crisis" of the 1970 and a considerable body of knowledge had been gained with the studies performed at the time. But, with the end of the crisis, these attempts were abandoned. Today, history repeats itself and the great surge in commodity prices of the early years of the 21st century has generated new interest in mining seawater.

This paper examines the perspectives of extracting metals from seawater mainly from the viewpoint of the energy involved. The analysis takes into account two possible strategies of extraction; one is pumping seawater through a selective membrane, the other dropping the membrane into the sea and exploiting the natural marine current to bring metal ions to the active membrane sites. Of the two methods, the first is more costly in terms of energy; the second is more complex and less efficient in terms of the use of the membrane. A specific benchmark in this analysis is that of the extraction of uranium, which can be used as energy source in fission reactors, since the future availability of mineral uranium from land mines has been questioned in several studies [6-8]. In this case, the critical parameter is EROEI.

The results of the energy analysis show that uranium extraction from seawater is an unfeasible process if carried out in connection with the present nuclear technology. For the other ions contained in seawater, energy remains a critical parameter determining the feasibility of extraction. The results show that for most ions dissolved in seawater, the energy involved in extraction is very large in comparison to the present world production. Therefore, using metals from seawater to offset ore depletion does not appear to be feasible, with lithium being a possible exception.

\section{Results and Discussion}

\subsection{Minerals in Seawater}

Open ocean water contains dissolved salts in a range of 33 to $37 \mathrm{~g} / \mathrm{L}$, corresponding to a total mass of some $5 \times 10^{16}$ tons for a total mass of water of about $1.3 \times 10^{18}$ tons. Extraction from this huge source is theoretically promising and has been considered in several studies performed in the 1970s [9,10]. The interest in mining the oceans is especially evident if we compare the amount of dissolved minerals to the total mass of minerals extracted today in the world; estimated to be in the order of a hundred billion tons $\left(1 \times 10^{11}\right.$ tons $)$ per year [11].

In the present work, we will consider only metals which appear normally as positive ions dissolved in seawater. The four most concentrated metal ions, $\mathrm{Na}^{+}, \mathrm{Mg}^{2+}, \mathrm{Ca}^{2+}$ and $\mathrm{K}^{+}$, are the only ones 
commercially extracted today, with the least concentrated of the four being potassium (K) at 400 parts per million (ppm). Below potassium, the next metal ion in order of decreasing concentration is lithium; at a value more than three orders of magnitude lower: $0.17 \mathrm{ppm}$. Noble metals and refractory metals exist in seawater at the opposite side of the concentration spectrum; in many cases in such minute concentrations that are impossible to determine with certainty.

The concentration of ions in seawater depends mainly by two factors: their crustal abundance and the existence of water-soluble species. These two constraints account for the spread in the concentration values. As an example, thorium and uranium are both usable as fuel for fission plants, but uranium exists in seawater at concentrations about four orders of magnitude larger than thorium. This is due to the different chemistry of the two ions. Thorium is present mainly as scarcely soluble hydroxide, whereas uranium exists as the much more soluble uranyl carbonate complexes [12-14].

Table 1 lists the seawater concentrations and total amounts of some metal ions. The amounts available in seawater are compared with the land reserves listed by the United States Geological Survey (USGS) [15]. The reserves are mineral sources reasonably homogeneous in terms of composition, so it makes sense to compare reserves to the amount of ions dissolved in seawater, which is also a homogeneous resource in terms of composition. "Mineral resources", the other concept commonly used in this field, often implies a different composition and different geological and or technological constraints. Also note that the concept of "reserves" may be a realistic estimate of what we can actually extract from land mines [3]. Table 1 shows the presence of huge amounts of minerals in the sea, in most cases considerably larger than the estimated reserves on land.

Table 1. Concentrations and estimated amounts of dissolved metal ions in the sea, compared with the estimated land resources.

\begin{tabular}{|c|c|c|c|}
\hline Element & $\begin{array}{c}\text { Concentration in } \\
\text { seawater (ppm) }\end{array}$ & $\begin{array}{c}\text { Total oceanic abundance } \\
\text { (tons) }\end{array}$ & $\begin{array}{c}\text { Mineral reserves on } \\
\text { Land (tons) }\end{array}$ \\
\hline $\mathrm{Na}$ & 10,800 & $1.40 \times 10^{16}$ & - \\
\hline $\mathrm{Mg}$ & 1,290 & $1.68 \times 10^{15}$ & $2.20 \times 10^{9}$ \\
\hline $\mathrm{Ca}$ & 411 & $5.34 \times 10^{14}$ & - \\
\hline $\mathrm{K}$ & 392 & $5.10 \times 10^{14}$ & $8.30 \times 10^{9}$ \\
\hline $\mathrm{Li}$ & 0.178000 & $2.31 \times 10^{11}$ & $4.10 \times 10^{6}$ \\
\hline $\mathrm{Ba}$ & 0.021000 & $2.73 \times 10^{10}$ & $1.90 \times 10^{8}$ \\
\hline $\mathrm{Mo}$ & 0.010000 & $1.30 \times 10^{10}$ & $8.60 \times 10^{6}$ \\
\hline $\mathrm{Ni}$ & 0.006600 & $8.58 \times 10^{9}$ & $6.70 \times 10^{7}$ \\
\hline $\mathrm{Zn}$ & 0.005000 & $6.50 \times 10^{9}$ & $1.80 \times 10^{8}$ \\
\hline $\mathrm{Fe}$ & 0.034000 & $4.42 \times 10^{9}$ & $1.50 \times 10^{11}$ \\
\hline $\mathrm{U}$ & 0.003300 & $4.29 \times 10^{9}$ & $2.60 \times 10^{6}-5.47 \times 10^{6}$ \\
\hline $\mathrm{V}$ & 0.001900 & $2.47 \times 10^{9}$ & $1.30 \times 10^{7}$ \\
\hline $\mathrm{Ti}$ & 0.001000 & $1.30 \times 10^{9}$ & $7.30 \times 10^{8}$ \\
\hline $\mathrm{Al}$ & 0.001000 & $1.30 \times 10^{9}$ & $2.50 \times 10^{10}$ \\
\hline
\end{tabular}


Table 1. Cont.

\begin{tabular}{|c|c|c|c|}
\hline Element & $\begin{array}{c}\text { Concentration in } \\
\text { seawater (ppm) }\end{array}$ & $\begin{array}{c}\text { Total oceanic abundance } \\
\text { (tons) }\end{array}$ & $\begin{array}{c}\text { Mineral reserves on } \\
\text { Land (tons) }\end{array}$ \\
\hline $\mathrm{Cu}$ & 0.000900 & $1.17 \times 10^{9}$ & $4.90 \times 10^{8}$ \\
\hline $\mathrm{Mn}$ & 0.000400 & $5.20 \times 10^{8}$ & $4.60 \times 10^{8}$ \\
\hline $\mathrm{Co}$ & 0.000390 & $5.07 \times 10^{8}$ & $7.00 \times 10^{8}$ \\
\hline $\mathrm{Sn}$ & 0.000280 & $3.64 \times 10^{8}$ & $6.10 \times 10^{6}$ \\
\hline $\mathrm{Cr}$ & 0.000200 & $2.60 \times 10^{8}$ & $4.75 \times 10^{8}$ \\
\hline $\mathrm{Cd}$ & 0.000110 & $1.43 \times 10^{8}$ & $4.90 \times 10^{5}$ \\
\hline $\mathrm{Pb}$ & 0.000030 & $3.90 \times 10^{7}$ & $7.90 \times 10^{7}$ \\
\hline $\mathrm{Au}$ & 0.000011 & $1.43 \times 10^{7}$ & $4.20 \times 10^{4}$ \\
\hline $\mathrm{Th}$ & 0.0000004 & $5.20 \times 10^{5}$ & $1.30 \times 10^{6}$ \\
\hline
\end{tabular}

Seawater element concentrations are taken from [16]. Oceanic abundance is calculated assuming a total ocean volume of $1.3 \times 10^{9} \mathrm{~km}^{3}\left(1.3 \times 10^{18}\right.$ tons). Mineral reserves are from USGS data [15] except for uranium reserves; for which two values are given, the smaller one from [8] and the larger one from [6]. The USGS [15] does not provide data for the world reserves of sodium and calcium. All land reserves are in terms of the pure element, except for aluminium, iron, potassium, thorium and titanium, given in terms of oxides. The table does not list elements contained in extremely minute traces in seawater. Thorium is shown as an exception, because of its potential importance as nuclear fuel, although obviously the value reported only suggests an order of magnitude.

\subsection{Extraction Techniques}

Traditionally, the most concentrated ions in seawater (e.g., minerals such as sodium chloride) were concentrated and extracted from seawater by evaporation. Ions such as $\mathrm{Mg}$ or $\mathrm{K}$ can subsequently be recovered by electrolytical processes. These methods are not practical for low concentration ions, for which the most general extraction method is to pump seawater through a membrane containing functional groups that selectively bind to the species of interest. No known membrane is $100 \%$ selective, but it is possible to create membranes that can retain a small number of species. The adsorbates can be extracted from the membrane by flushing it with appropriate chemicals, a process called "elution". After this stage, the metal ions can be separated and recovered by precipitation or electrodeposition.

The scientific literature reports only two recent cases of experimental tests of extraction from the sea of ions other than the four most concentrated ones: lithium [9] and uranium [10,17]. None of these attempts led to the development of commercial processes.

The problem with extracting minerals from seawater lies in the huge amounts of water that need to be processed. Table 2 shows an estimate of these amounts 
Table 2. The masses of seawater that must be filtered in order to obtain the elements of technological interest at present traditional mining production scale.

\begin{tabular}{|c|c|c|c|}
\hline Element & $\begin{array}{c}\text { Total mass in } \\
\text { oceans (tons) }\end{array}$ & $\begin{array}{c}\text { Production in 2007 } \\
\text { (tons) }\end{array}$ & $\begin{array}{c}\text { Mass of water to be } \\
\text { processed (tons) }\end{array}$ \\
\hline $\mathrm{Li}$ & $2.31 \times 10^{11}$ & $2.50 \times 10^{4}$ & $1.40 \times 10^{11}$ \\
\hline $\mathrm{Mo}$ & $1.30 \times 10^{10}$ & $1.87 \times 10^{5}$ & $1.87 \times 10^{13}$ \\
\hline $\mathrm{U}$ & $4.29 \times 10^{9}$ & $6.65 \times 10^{4}$ & $2.02 \times 10^{13}$ \\
\hline $\mathrm{V}$ & $2.47 \times 10^{9}$ & $5.86 \times 10^{4}$ & $3.08 \times 10^{13}$ \\
\hline $\mathrm{Cd}$ & $1.43 \times 10^{8}$ & $1.99 \times 10^{4}$ & $1.81 \times 10^{14}$ \\
\hline $\mathrm{Au}$ & $1.43 \times 10^{7}$ & $2.50 \times 10^{3}$ & $2.27 \times 10^{14}$ \\
\hline $\mathrm{Sn}$ & $3.64 \times 10^{8}$ & $3.00 \times 10^{5}$ & $1.07 \times 10^{15}$ \\
\hline $\mathrm{Ni}$ & $8.58 \times 10^{8}$ & $1.78 \times 10^{6}$ & $2.69 \times 10^{15}$ \\
\hline $\mathrm{Cu}$ & $1.17 \times 10^{9}$ & $1.56 \times 10^{7}$ & $1.73 \times 10^{16}$ \\
\hline $\mathrm{Mn}$ & $5.20 \times 10^{8}$ & $1.16 \times 10^{7}$ & $2.90 \times 10^{16}$ \\
\hline $\mathrm{Zn}$ & $6.50 \times 10^{9}$ & $1.80 \times 10^{8}$ & $3.60 \times 10^{16}$ \\
\hline $\mathrm{Al}$ & $1.30 \times 10^{9}$ & $3.80 \times 10^{7}$ & $3.80 \times 10^{16}$ \\
\hline $\mathrm{Cr}$ & $2.60 \times 10^{8}$ & $2.00 \times 10^{7}$ & $1.00 \times 10^{17}$ \\
\hline $\mathrm{Pb}$ & $3.90 \times 10^{7}$ & $3.55 \times 10^{6}$ & $1.18 \times 10^{17}$ \\
\hline $\mathrm{Fe}$ & $4.42 \times 10^{9}$ & $2.26 \times 10^{9}$ & $6.65 \times 10^{17}$ \\
\hline $\mathrm{Ti}$ & $1.30 \times 10^{6}$ & $6.10 \times 10^{6}$ & $2.77 \times 10^{17}$ \\
\hline $\mathrm{Co}$ & $5.07 \times 10^{8}$ & $6.23 \times 10^{7}$ & $1.59 \times 10^{17}$ \\
\hline
\end{tabular}

\footnotetext{
a The values are hypothetical calculations that yield the production figures of the corresponding elements at an optimistic assumption of $100 \%$ efficiency of the filtering membrane. Seawater elements concentration are from [16]. Oceanic abundance is calculated assuming a total ocean volume of $1.3 \times 10^{9} \mathrm{~km}^{3}$. Mineral production data are from [15] except for uranium data, which is from [8]. In this case, the value reported is the total uranium consumption rather than the mineral production, which is about $2 / 3$ of the total.
}

In examining the table, consider, as a comparison, that the total volume of water desalinated today is in the order of ten billion tons ([18] reports a value of $1.6 \times 10^{10}$ tons). Even for the most favourable case, lithium, the table shows that the amount of water to be processed is at least ten times larger. Moving these enormous amounts of water is not just a practical problem; it involves energy. This parameter is especially critical if we consider the extraction of two elements that are to be used as energy sources: lithium and uranium. Uranium, in the form of ${ }^{235} \mathrm{U}$, is the fuel of the present generation of nuclear fission plants. Lithium, in the form of the ${ }^{6} \mathrm{Li}$ isotope, could be a source of tritium, which can be used as fuel for a future generation of fusion power plants. In both cases, the feasibility of extraction is determined by the energy needed according to the well-known concept of EROEI [5]. The 
case of uranium will serve as a benchmark for evaluating the feasibility of extraction of all the other elements.

\subsection{Uranium Extraction from Seawater}

The present supply of mineral uranium is only in part (about 60\%) guaranteed by mineral sources; the rest is being obtained from stockpiled uranium resources derived in large part from dismantled atomic warheads [8]. Increasing uranium production from land mines would require large investment and, eventually, the increasing energy requirement of uranium extraction from low grade ores could make the whole activity self-defeating [7,8]. To give some idea of the requirements, consider that a 1 GWe nuclear plant needs about 170 tons of natural uranium per year, or 6 grams per second.

As shown in the previous section, the amount of uranium theoretically available in the oceans is more than sufficient to stave off all worries of shortages for a long time. The development of a synthetic membrane able to selectively recover uranium from seawater [19] was an important step forward in this field, and it led to experimental tests performed in the 1990s by researchers of the Japanese Atomic Energy Agency (JAEA). In a series of experiments apparently performed in 1996-1997, a few grams of uranium oxide were actually recovered from seawater, although scant data were reported on the process and methods utilized [17]. Later results obtained using braided fiber as adsorbent are reported in a web page in the JAEA site [20]. Reports about studies on this field have appeared in press releases from JAEA but it does not appear that, at present, there exists an active experimental program of uranium extraction from seawater.

A complete evaluation of the results of the JAEA research program is not possible, at present, for the lack of sufficient data. However, we can develop an approximate evaluation of the EROEI of uranium extraction from seawater considering that, from Table 2, we would need to process at least $2 \times 10^{13}$ tons of water every year in order to produce enough fuel for the present fleet of nuclear reactors. This amount is more than one thousand times the amount of water desalinated today and that gives an idea of the size of the task. Another way of appreciating the size of this mass of water is to consider that it is about the same as that of the whole North Sea.

In order to process this mass of water, there are two possible strategies: one is to actively pump seawater through the membrane, the other to simply drop the membrane in the sea and wait for the metal ions to migrate to the active sites. In both cases, energy is needed for a variety of operations: building infrastructure, moving the membranes, manufacturing them, etc. We do not have enough data for a step-by-step evaluation of the energy necessary, but we can estimate its order of magnitude by comparing with known processes.

Pumping water through a membrane requires energy mainly because of the viscosity of water. This effect is described by Darcy's law, which says that the energy required to flow water through a porous membrane is inversely proportional to a parameter called "permeability". A finer membrane (e.g., sand) has a lower permeability than a coarse membrane (e.g., gravel). The permeability of a uranium extraction membrane is not reported in available studies and it is probably not even known at the present stage. However, we can estimate the energy involved by comparing with a similar known process: desalination by reverse osmosis, where water is also pumped through a membrane just as it would be done for uranium extraction. 
The energy involved in desalination by reverse osmosis is normally reported as in the order of 2-4 kWh/ton. A recent study [21] reports a "state of the art" value of $2.5 \mathrm{kWh} / \mathrm{ton}$. For uranium separation, membranes cannot have a too different value of the permeability and, therefore, the energy needed cannot be too different. On this basis, we can calculate the EROEI of the process. Consider that the present worldwide production of nuclear energy is about $2.5 \times 10^{3}$ TWh (terawatt-hour) per year [7] and that we need to process $2 \times 10^{13}$ tons of water per year (see Table 2) to produce a sufficient amount of uranium. Therefore, the "energy density" of seawater in terms of energy that can be produced by the present nuclear technology is about $0.1 \mathrm{kWh} / \mathrm{ton}$. If we need $2.5 \mathrm{kWh} / \mathrm{ton}$ for extraction then the EROEI is less than 0.1 and the process has no practical interest as a source of fuel for fission plants. This result agrees with previous estimations based on different considerations that led to the same conclusion [9].

The second possible strategy of extraction is to drop the membrane into the sea and wait for currents or thermal diffusion to bring the uranium to the adsorbing sites. This method avoids the energy cost of pumping. Yet, it is also a less efficient way to use the membrane. As a consequence, we need a larger mass of membranes, a larger infrastructure, and we need to move the membranes in and out of the sea, all of which incurs energy costs.

We can examine the feasibility of the process using an order of magnitude estimate. As before, we see from Table 2 that we need to process at least $2 \times 10^{13}$ tons of water per year to produce enough uranium for the current park of nuclear reactors in the world. To process this amount of water, we must rely on oceanic currents to move water through the membranes. In marine science, current strength is sometimes measured in "Sverdrups", a unit that corresponds to one million tons of water per second, or $3 \times 10^{13}$ tons of water per year. So, 1 Sverdrup is almost exactly the flow of seawater that carries enough uranium for the present needs of the world's nuclear plants. Some oceanic currents are reported to be much stronger than 1 Sverdrup. For instance, perhaps the strongest current in the world is the Antarctic Circumpolar Current (ACC) which corresponds to about 135 Sverdrups. But the average depth of the Southern (Antarctic) Ocean is around 3,000-4,000 m, and the area is highly hostile to human activities. Anchoring there millions of tons of adsorbing membranes, together with all the processing facilities, is simply unthinkable.

A more realistic possibility is the Strait of Gibraltar which carries a current of about 1 Sverdrup. Damming the strait in order to produce energy had already been proposed by Herman Sorgel in the 1920s with his concept of the "Atlantropa" dam. Of course, damming the strait would be an environmental disaster of a magnitude that is difficult to even estimate. However, we might think of intercepting $10 \%$ of the currents of the Gibraltar strait causing (perhaps) not too high environmental problems. In this case, the system would provide about $10 \%$ of the uranium fuel needed today in the world. For the current needs of the nuclear industry, we would need the equivalent of 10 Straits of Gibraltar; in practice many more, because the process could not be $100 \%$ efficient. In order to match the present world's demand of electricity, we would need at least 60 equivalent straits, more likely at least a hundred. A larger number would be needed if we were to increase electric power production to match the presently produced energy from fossil fuels. It seems unlikely that there could exist hundreds of sites in the world that might be considered equivalent to the Strait of Gibraltar in terms of marine currents and vicinity to land. In any case, the environmental impact of the task would be enormous and beyond imagination. 
These considerations provide us with a certain perspective of the size of the process we are examining. From here, we can move to the evaluation of the critic parameter of the process: EROEI. Again, we lack sufficient data for a quantitative analysis of the process, but we can compare with a similar process: oceanic fishing.

From data about the energy expenditure of the fishing industry [22] we can estimate that the industry uses fuel for about $7 \mathrm{kWh}$ for each kilogram of fish recovered. Another estimate derives from knowing that the total world fish catch in 2003 was of 90 million tons $\left(9 \times 10^{10} \mathrm{~kg}\right)$ per year [23], while the total amount of fuel used by the world's fishing fleet in 2005 was of some 14 million tons of diesel fuel [24] $\left(2 \times 10^{11} \mathrm{kWh}\right.$, considering that the energy content of diesel fuel is $\left.43 \mathrm{GJ} / \mathrm{ton}\right)$. The result is about $2 \mathrm{kWh}$ of energy per kilogram of fish landed. These are rough estimates that only take into account the fuel cost. Yet, it is known that fuel is the main energy expenditure involved in ocean fishing. So, a mid-range value of $5 \mathrm{kWh} / \mathrm{kg}$ cannot be too far off in terms of the energy cost of extracting something from the open sea and bringing it back to land.

Now, we have to consider a process where membranes for uranium extraction are carried at sea, submerged for a while, raised, brought back to land for processing, and then the cycle is repeated. From the data reported in [17] we can calculate that we need about $300 \mathrm{~kg}$ of membrane per kilogram of uranium extracted per year. We also read in the paper that the membranes were "pulled out of seawater using a crane ship every 20 to 40 days". In other words, the membranes have to be brought back to the elution facility every month or so. Recovering one kilogram of uranium, therefore, would require processing at least 3 tons of membranes per year. For the present worldwide uranium demand (6.5 $\times 10^{4}$ tons/year), $2 \times 10^{8}$ tons of membrane need to be processed every year; considerably larger than the weight of the total catch of today’s fishing industry $\left(9 \times 10^{7}\right)$. This is another indication of the colossal size of the task.

But the important parameter is the energy involved. Using the ratio of $5 \mathrm{kWh} / \mathrm{kg}$ for energy expenditure in fishing, and assuming the yield and the conditions reported by Seko [17], we can calculate a total energy expenditure of about $1 \times 10^{3} \mathrm{TWh} /$ year for processing the membranes to give sufficient amounts to fuel the present needs of the nuclear industry. This is close to the total energy that could be produced by the extracted uranium, ca. $2.5 \times 10^{3} \mathrm{TWh} /$ year [7]. An energy gain (EROEI) of 2.5 is larger than unity, but it is too low for the process to be of practical interest.

We need also to consider that these membranes are synthetic chemicals that would be obtained starting from crude oil or natural gas, and that the crude oil used as feedstock is lost as an energy source. We can make a rough evaluation of this energy considering that, as an educated guess, we may consider a yield of $30 \%$ in the synthesis process and conclude that we need about one ton of crude oil as the feedstock for $300 \mathrm{~kg}$ of membranes [17] able to produce $1 \mathrm{~kg}$ uranium per year. Since crude oil has an energy content of about $12 \mathrm{kWh} / \mathrm{kg}$, we would be using an equivalent of some $12 \mathrm{MWh}$ that, if used in a high efficiency combined cycle gas turbine, would produce about $6 \mathrm{MWh}$ of electric power. One kilogram of uranium in a nuclear fission plant can generate about $40 \mathrm{MWh}$ of electric power, so the result is an overall gain only if the membranes can last for a few months at least, but the energy involved in manufacturing the membranes is not negligible, and it would negatively impact the overall EROEI of the process.

Of course, there is a high level of uncertainty in these calculations. On the one hand, we need to consider that it is possible to improve the efficiency of extraction process using braided membranes 
and working at higher sea temperatures [25]. We might also build floating processing facilities in order to reduce the transportation costs. On the other hand, the EROEI calculation refers only to the fuel expenditures. To that, we still need to add all the costs for the infrastructure, for the chemicals used in elution, for the energy needed to recover the species of interest, etc.

We can conclude that uranium extraction from seawater has a low EROEI. The process is almost certainly unfeasible (EROEI less than one) if carried out by pumping seawater through an adsorbing membrane. The EROEI is also likely too low to be of interest for a process where membranes are dispersed in the sea, not to mention that in both cases, the environmental damage associated with extraction would be huge.

\subsection{Lithium and Other Minerals}

The case of uranium can be used as a benchmark for evaluating the perspectives of extracting all other elements. First of all, we should consider lithium, which is the most abundant ion in the sea after the four ones commercially extracted at present ( $\mathrm{Na}, \mathrm{Mg}$, Ca and $\mathrm{K}$ ). Lithium is used for a variety of technological applications, including batteries for vehicles. One of the lithium isotopes, ${ }^{6} \mathrm{Li}$, could be transformed into an isotope of hydrogen, tritium, which in turn could be the fuel of a future generation fusion reactor.

The uncertainties involved in the operation of a future commercial fusion reactor are very large. Nevertheless, it is crucial to understand whether fuel availability for such reactors will be a critically limiting factor. Fasel and Tran [26] estimate that a water-cooled lithium-lead breeder blanket reactor of 1.5 GWe power will need 787 tons of lithium per year. Other possible technologies are considered in the study, but this one seems to be the closest to a future fusion technology. This reactor could produce 12 TWh of energy per year. From the data in Table 2, we see that to produce 800 tons of lithium, we need to process $4 \times 10^{9}$ tons of seawater. In other words, the "energy density" of seawater in terms of fusion plants would be about $3 \mathrm{kWh} / \mathrm{ton}$, more than an order of magnitude larger than it is in terms of fission plants $(0.1 \mathrm{kWh} / \mathrm{ton})$.

If efficient selective membranes for lithium adsorption can be developed, the energy involved in extraction would likely be about the same as for uranium, but we would need ten times less water for the same amount of lithium, hence ten times less energy. Extraction by active pumping would still be a poor prospect in terms of EROEI, but submerged membranes might achieve good values of the EROEI. This result is highly uncertain in view of the lack of knowledge on the characteristics of future fusion reactors, nevertheless it is possible at least to state that lithium extraction from seawater cannot be ruled out as a source of fuel.

Lithium is also an essential element for a new generation of batteries, especially for road vehicles. Tahil [27] studied the availability of mineral lithium if we were to substitute the present vehicle fleet with vehicles based on lithium batteries, and concluded that, in the long run, we would face a lithium shortage if the present growth trends were maintained. Therefore, extraction from seawater might be an important method to supply lithium for the growing needs of the transportation industry. From Table 2 we see that if we were to get the present lithium mineral production by filtering ocean water through a membrane, we would need around $1.5 \times 10^{3} \mathrm{TWh}$, which is less than $10 \%$ of the present world production of electric power (ca. $2 \times 10^{4}$ TWh per year). It is a large amount but not 
unconceivable. Using submerged membranes, we would be able to substantially reduce that amount of energy, perhaps of one order of magnitude. Finally, if we were to use lighter and more efficient vehicles, we would further reduce the amount of lithium needed.

In any case, we do not need to consider the sea as the sole source of the lithium we use. Recycling what we use would considerably reduce needs. The recycling of battery materials is a well-known process; with lead batteries being today recycled at a rate of approximately $90 \%$ [28], so it is reasonable to think that the same level of recycling could be attained for lithium. Although it will never be possible to recycle at the $100 \%$ level, lithium from seawater could provide the amount lost in inefficient recycling, provided that it can be maintained at the level of a few percents of the total. If, for instance, we were able to recycle lithium at $99 \%$, we would need only $1 \%$ of the present supply from seawater. That would correspond to an energy expenditure of just $0.1 \%$ of the present worldwide power production. In this case, therefore, the oceans could act as an "infinite reservoir", allowing the industrial system to close the production cycle and generating a sustainable supply for the economy, in principle, forever.

Unfortunately, this strategy appears feasible only for the case of lithium. For all other elements listed in Table 1, extraction from seawater in sufficient amounts is impossible or at least extremely difficult. Consider copper as an example. Recovering from the sea the current yearly production would require processing ca. $2 \times 10^{16}$ tons of water. If we take the value, calculated for uranium, of $1 \mathrm{kWh} /$ ton of energy needed for filtering water through a membrane, the total energy needed amounts to $2 \times 10^{8} \mathrm{TWh}$, four orders of magnitude larger than the current yearly production of electric energy. Even if we were able to manage so much energy, the total amount of copper that exists in the oceans is only about 50 times the current yearly production (see Table 2). So, in 50 years we would run out of copper from seawater, even if we were able to filter all the water in the planet's oceans.

Consider a different approach: what amounts of minerals could be recovered in practice if we were to extract them from the brine produced by the existing desalination plants? In that case, processing $1 \times 10^{10}$ tons of water would produce only about the $0.001 \%$ of the present world's copper production. At present, copper is recycled at around $76 \%$ in the USA and about $47 \%$ worldwide [29,30]. In order to make copper production from seawater significant, we would need to increase this ratio to levels totally impossible for the world's industrial system as it is today. The situation is better for some other elements such as vanadium, cadmium and molybdenum, but, also in these cases, the amounts which could be produced are in the order of $0.1 \%$ of the present production. The world's industrial system has not been conceived for recycling ratios that would make such kind of recovery useful. However, it would be too much to say that the task is utterly impossible, since it is, after all, the strategy used by the world's ecosystem. A rough estimate of the amount of copper cycled by the continental biomass is of the order of $1 \times 10^{4}$ tons per year [32,33]. It is a very small amount compared to the human copper production ( $\mathrm{ca} .1 \times 10^{7}$ tons per year), but land plants never ran out of copper over at least 300 million years of existence on this planet.

\section{Conclusions}

Adding together very large volumes of low concentration mineral resources easily leads to optimistic estimates of availability "when the market price will be right". But this optimism is 
misplaced. Prices are just tags stuck on mineral resources by human beings and have no physical reality. It does not matter how expensive a mineral commodity can be in monetary terms: what counts is that extracting it must not require more energy than what the economic system can produce [29]. In the case of minerals used as energy sources, the EROEI of extraction from seawater, processing and using must be significantly larger than one.

Energy requirements are determined by concentration. The extraction from low concentration resources, no matter in seawater or in the earth's crust, is expensive in terms of the energy needed. The analysis presented here shows that, for most elements, extraction from seawater is so energy expensive that it must be considered beyond our possibilities in the short and medium term. The exceptions are the four high concentration elements already being commercially extracted ( $\mathrm{Na}, \mathrm{Mg}, \mathrm{Ca}, \mathrm{K}$ ) and perhaps lithium, which might become a critically important element for a future economy that would rely on lithium batteries for transportation and-perhaps-on fusion energy. All other elements could be extracted from seawater only in amounts too small to be useful for the present industrial economy.

\section{References and Notes}

1. Wouters, H.; Bol, D. Material Scarcity; Report of the Materials Innovation Institute; Available online: http://www.materialscarcity.nl/systems/file_download.aspx?pg=162\&ver=1 (accessed on 10 March 2010).

2. Gordon, R.B.; Bertram, M.; Graedel, T.E. Metal stocks and sustainability. Proc. Nat. Acad. Sci. USA 2006, 103, 1209-1214.

3. Bardi U.; Pagani, M. Peak Minerals. The Oil Drum, 15 October 2007; Available online: http://www.theoildrum.com/node/3086 (accessed on 10 March 2010).

4. Bardi, U.; Lavacchi, A. A simple interpretation of Hubbert's model of resource exploitation. Energies 2009, 2, 646-661.

5. Hall, C.A.S.; Cleveland, C.J.; Kaufmann, R.K. Energy and Resource Quality. In The Ecology of the Economic Process; Wiley Interscience: New York, NY, USA, 1992.

6. World Nuclear Association (WNA). World Uranium Mining, 2009; Available online: http://www.world-nuclear.org/info/inf23.html (accessed on 10 March 2010).

7. Dittmar, M. The Future of Nuclear Energy: Facts and Fiction Part III: How (un)Reliable Are the Red Book Uranium Resource Data? The Oil Drum, 8 September 2009; Available online: http://www.theoildrum.com/pdf/theoildrum_5744.pdf (accessed on 10 March 2010).

8. Energy Watch Group. Uranium Resources and Nuclear Energy, 2006; Available online: http://www.energywatchgroup.org/fileadmin/global/pdf/EWG_Report_Uranium_3-122006ms.pdf (accessed on 10 March 2010).

9. Schwochau, K. Extraction of Metals from Sea Water. In Springer Series “Topics in Current Chemistry"; Springer: Heidelberg, Germany, 1984.

10. Nebbia, G. L'estrazione di Uranio dall'acqua di mare, 1970; Available online: http://www.aspoitalia.it/component/content/article/192 (accessed on 10 March 2010).

11. Office for Official Publications of the European Communities. Environmental Signals; Available online: http://reports.eea.europa.eu/signals-2000/en/page017.html (accessed on 10 March 2010). 
12. Santschi, P.H.; Murray, J.W.; Baskaran, M.; Benitez-Nelson, C.R.; Guo, L.D.; Hung, C.C.; Lamborg, C.; Moran, S.B.; Passow, U.; Roy-Barman, M. Thorium speciation in seawater. Mar. Chem. 2006, 100, 250-268.

13. Strohal, P.; Pinter, T. Thorium in water and algae from the Adriatic Sea. Limnol. Oceanogr.-Methods 1973, 18, 250-253.

14. Saito, K.; Miyauchi, T. Chemical Forms of Uranium in Artificial Seawater. J. Nucl. Sci. Technol. 1982, 19, 145-150.

15. United States Geological Survey (USGS). Mineral Commodities Summary; Available online: http://minerals.usgs.gov/minerals/pubs/mcs/index.html (accessed on 21 July 2009).

16. Floor Anthoni, J. Oceanic Abundance of Elements; Available online: www.seafriends.org.nz/oceano/seawater.htm (accessed on 7 March 2010).

17. Seko, N.; Katakai, A.; Hasegawa, H.; Tamada, M.; Kasai, N.; Takeda, H.; Sugo, T.; Saito, K. Aquaculture of Uranium in Seawater by a Fabric-Adsorbent Submerged System. Nucl. Technol. 2003, 144, 274-278.

18. Kranhold, K. Water, water everywhere.... The Wall Street Journal, 17 January 2008, p. B1; Available online: http://online.wsj.com/article/SB120053698876396483.html (accessed on 10 March 2010).

19. Vernon, F.; Shah, T. The extraction of uranium from seawater by poly(amidoxime)/poly(hydroxamic acid) resins and fibre. React. Polym., Ion Exchange., Sorbents 1983, 1, 301-308.

20. Zhang, A.Y.; Asakurak, T.; Uchiyama, G. The adsorption mechanism of uranium(VI) from seawater on a macroporous fibrous polymeric adsorbent containing amidoxime chelating functional group. React. Funct. Polym. 2003, 57, 67-76.

21. Stover, R.L. Evolution of energy consumption in seawater reverse osmosis. Desalination Water Reuse 2009, 18, 27-30.

22. Mitchell, C.; Cleveland, C.J. Resource scarcity, energy use and environmental impact: A case study of the New Bedford, Massachusetts, USA, fisheries. J. Environ. Manage. 1993, 17, 305.

23. Larse, J. Wild Fish Catch Hits Limits-Oceanic Decline Offset by Increased Fish Farming; Earth Polcicy Institute Report, 22 June 2005; Available online: http://www.earth-policy.org/Indicators/ Fish/2005.htm (accessed on 10 March 2010).

24. FAO: The State of World Fisheries and Aquaculture-2006; FAO Corporate Report, 2006; Available online: http:/www.fao.org/docrep/009/a0699e/A0699E08.htm (accessed on 21 November 2009).

25. Tamada, M. Collection of Uranium from Seawater; Available online: http://www.iaea.org/OurWork/ST/NE/NEFW/documents/RawMaterials/TM_Vienna2009/present ations/22_Tamada_Japan.pdf (accessed on 1 December 2009).

26. Fasel, D.; Tran. M.Q. Availability of lithium in the context of future D-T fusion reactors. Fusion Eng. Des. 2005, 75, 1163-1168.

27. Tahil, W. The Trouble with Lithium Implications of Future PHEV Production for Lithium Demand, 2006; Available online: http://tyler.blogware.com/lithium_shortage.pdf (accessed on 10 March 2010). 
28. Sloop, S.E.; Kotaich, K.; Ellis, T.W.; Clarke, R. RECYCLING | Lead-Acid Batteries: Electrochemical. In Evolution of Sedimentary Rocks, Encyclopedia of Electrochemical Power Sources; Garche, J., Ed.; Elsevier: Amsterdam, The Netherlands, 2009; pp.179-187.

29. Bardi, U. The Universal Mining Machine; Available online: http://europe.theoildrum.com/ node/3451m 2008 (accessed on 10 March 2010).

30. Copper Development Association Homepage. http://www.copper.org/environment/g_recycl.html (accessed on 14 December 2009).

31. Graedel, T.E.; van Beers, D.; Bertram, M.; Fuse, K.; Gordon, R.B.; Gritsinin, A.; Kapur, A.; Klee, R.J.; Lifset, R.J.; Memon, L.; Rechberger, H.; Spatari, S.; Vexler, D. Multilevel Cycle of Anthropogenic Copper. Environ. Sci. Technol. 2004, 38, 1242-1252.

32. Garrels, R.M.; Mackenzie, F.T. Evolution of Sedimentary Rocks; W.W. Norton: New York, NY, USA, 1971; pp. 104-106.

33. Bardi, U. Il Pianeta dei Minatory; Available online: http:/www.aspoitalia.it/attachments/ 142_pianetaminatori.pdf (accessed on 3 March 2010).

(C) 2010 by the authors; licensee Molecular Diversity Preservation International, Basel, Switzerland. This article is an open-access article distributed under the terms and conditions of the Creative Commons Attribution license (http://creativecommons.org/licenses/by/3.0/). 